\title{
Sciendo
}

\section{G and Digital Sovereignty of the EU: The Slovak Way}

\section{Tomáš Gábriš Ondrej Hamul'ák}

Palacký University Olomouc

Faculty of Law

Tr. 17. Listopadu 8

Olomouc 771 11, Czech Republic

Email: tomas.gabris@upol.cz Email: ondrej.hamulak@upol.cz

\begin{abstract}
Some recent views question the concept of sovereignty (especially the sovereignty of states), arguing that sovereignty is to be abandoned as a historical concept, because it existed in the world of the Westphalian system (created after 1648), where states were the major players, centers of power and objects of interest. Instead, we suggest that sovereignty should be perceived again as a "supreme power" (summa potestas), meaning a return to the pre-Bodinian concept of sovereignty and perceive it as a "power to exert control". With regard to cyberspace, this does not mean direct control of all entities in the cyberspace, but only those that provide services which are perceived as "essential" or "critical" for the security and interests of the state. That is actually the approach taken with regard to ensuring the safety of $5 \mathrm{G}$ networks-through control imposed on the network operators, as required by the respective EU legislation and the EU Toolbox on $5 G$ Networks specifically.
\end{abstract}

Keywords: 5G EU Toolbox, 5G networks, cybersecurity, EU digital sovereignty 


\section{Introduction}

The problem of digital sovereignty can be basically reduced to protecting national interests in cyberspace. As Tropina and Callanan righty point out, the major challenge in this respect that the national governments and also $\mathrm{EU}$ are facing, is the "nonhierarchical structure and the borderless nature of the information and communication networks that do not fit the traditional top-down command-and-control models" (Tropina \& Callanan, 2015, p.12). One of the possible responses to regulation of cyberspace in this situation is the involvement of autonomous self-regulatory mechanisms or the use of co-regulatory approaches.

A manifestation of this can be seen in the way how cybersecurity norms introduced by the EU recently are being formulated-Directive 2016/1148 (2016), Regulation 2019/881 (2019) and finally also within its involvement in the protection of new generation of networks-5G (NIS Cooperation Group, 2020a). The road the EU is thereby taking is that of identifying entities that are to be imposed specific obligations with respect to the protection of the most important (critical, essential) services and infrastructures, while often it is left for the entities (and/or national governments) to specify the ways how to ensure compliance with the overall EU cybersecurity goals (Andraško, Mesarčík \& Hamulák, 2021).

Ensuring compliance with the bold aims of EU legislation is a specific feature of the legislative technique and regulatory approach applied in the EU. Ensuring the security of $5 \mathrm{G}$ networks in the EU is no exception to this rule. Namely, a rather general EU Toolbox of risk-mitigating measures for cybersecurity of $5 \mathrm{G}$ networks leaves it to the EU Member States to introduce national legislation best matching the standards recommended by the EU. This is precisely where some brief comparison might be of use for those Member States which have not yet implemented the expected measures. Often, even the method of how to do this remains questioned in these countries-Slovakia being no exception to this. Thus, we shall offer here an example of the Slovak Republic, which is currently working on drafting its amendment to its national Cybersecurity Act, but so far has apparently failed to take note of foreign models which can be of help here. A strong criticism from the side of security experts naturally opposed the first draft of the amendment being published in summer 2020. 
A detailed analysis of the proposed amendment as well as a summary of the best practices from abroad might be of help here even for readers and practitioners from outside Slovakia, in order to better grasp the challenge of protecting the $5 \mathrm{G}$ networks in line with the EU Toolbox recommendations.

\section{EU digital sovereignty}

The concept of sovereignty is both legal and philosophical. Legal theory distinguishes between sovereignty of people and sovereignty of states, being traditionally perceived as sovereigns in international relations-at least since the establishment of the Westphalian system of international law and relations (Kabat-Rudnicka, 2020; Hamulák, 2015).

From a historical point of view, it should be noted that although the European Middle Ages knew the term 'people' (populus), they did not know the term 'state' or 'sovereignty'. Still, instead of sovereignty, the Latin terms summa (plena) potestas, maiestas, or imperium were used to denote an idea close to sovereignty of states (Maiolo, 2007, p. 23). The famous contemporary French author Jean Bodin himself is considered to be the originator of the constitutional concept of sovereignty as we know it today, but in fact, the concept of sovereignty, without the express use of this term, can also be connected with his much earlier predecessor Bartolus of Saxoferrato (13131357 ) and with the traditional medieval concept of summa potestas or maiestas. Bodin in his work Les Six Livres de la République (1576), where he defined sovereignty as "absolute and eternal power over the republic" and claimed that no one before him had defined it, himself acknowledged that the notion was already known to the Romans as maiestas, to Greeks as kyrion archon and kyrion politeuma, to Renaissance Italians as segnoria, and to Jews as tomekh shebet. Nevertheless, despite the introduction of the term sovereignty, Bodin still did not abandon the continued use of the well-known terms maiestas, imperium, or summa potestas as traditional expressions of sovereignty (Maiolo, 2007, p. 84).

Moving to the present day now, some recent views have emerged that question the concept of sovereignty (especially the sovereignty of states), arguing that sovereignty is to be abandoned as a historical concept, because it existed in the world of the Westphalian system (created after 1648), where states were the major players, centers of power and objects of interest, while in a globalized world more and more power and competences is gained by 
intergovernmental and non-governmental organizations (Camilleri, 1992, p. 2, as quoted in Lindahl, 2006, p. 53).

Still, maybe even nowadays, sovereignty should and could be naturally perceived again as a 'supreme power' (summa potestas), i.e., we can return to the pre-Bodinian concept of sovereignty and perceive it as a "power to exert control". Still, while this is relatively easy to understand with respect to physical entities and specific territories, it needs reconsideration with respect to cyberspace just as the traditional concept of Bodinian state sovereignty had to be re-assessed in the past with regard to the challenges of outer space, sea or sky.

A similar problem thus arises nowadays with cyberspace, which consists of both physical (material) as well as immaterial elements, including social relations (Roguski, 2019). It might thereby be foolish to hope for the possibility to prevent citizens from "entering" the cyberspace or to prevent any crossborder transfer of data - these were namely proven to be easily and quickly circumvented by smart technological solutions being developed at a faster pace than any counter-measures developed and used by the states hoping for sovereignty in the cyberspace.

Instead of controlling the cyberspace properly, the regulatory authorities, traditional sovereigns, have therefore recently chosen a different approachnamely that of maiestas or summa potestas when controlling entities that fall under their competence in the analogue world, i.e. outside the cyberspace, meaning their citizens and legal persons registered or providing services in their territory. Of course, this does not mean direct control of all such entities with regard to their activities in the cyberspace, but only those that provide services which are perceived as "essential" or "critical" for the security and the interests of the sovereign (Hamulák et al., 2021). These are usually entities that provide access points to the cyberspace, or entities that need state licenses or permits in order to be allowed to provide their specific services in the territory controlled by traditional sovereign, or-in other terms - entities that can be effectively "tamed" by sanctions imposed by the sovereign. This solution thus represents a relatively simple way how to control the provision of crucial services and products within the scope of competences of a traditional sovereign, while at the same time giving up on the hopes to control each and every form of communication or transfer in the cyberspace. Again, this is rather the pre-modern concept of summa potestas rather than of state sovereign as an omnipresent and monopolistic regulator of all aspects of everyday life. That is actually the situation nowadays, e.g., 
with regard to the protection of personal data of the EU citizens in the fight with the mostly US-based tech giants and social media providers.

Understandably, this approach may not provide for absolute safety and control of cyberspace in the sense of eliminating any cyber incidents (cyberattacks or cybercrimes), since it is not an actual control of all the legally relevant activities in the cyberspace. It is rather to minimise negative phenomena and to provide for tools to cope with these quickly and efficiently-albeit by tools and powers of non-state entities entrusted with these tasks by the carrier of the supreme control powers. That is the main idea and concept of the functioning of digital sovereignty (supreme power in the cyberspace) in the EU as well as of all the national cybersecurity laws across the EU.

The EU (and any other traditional sovereign) attempting to build up its supreme control powers in cyberspace with respect to the entities falling into its competence, necessarily has to take into account the technological development in cyberspace and the growing dependence of almost all the sectors of traditional industry on electronic communications services and information society services in general. This will certainly be even more clearly visible once the $5 \mathrm{G}$ networks will be fully operational within the EU. ${ }^{1} 5 \mathrm{G}$ is namely expected to bring a revolution to both the everyday lives of EU citizens, as well as to the industry and market in Europe. In simple terms, it is expected to find application and use in many areas, first and foremost in the concept of the internet of things in general, but also particularly in broadband-like mobile services, connectivity for edge computing, development and use of artificial intelligence and their use in various sectors of industry.

It will thus become even more clear that the growing dependence on technology which could easily be targeted by an attack-at-distance, poses a threat and challenge to the security of any sovereign, both in political as well as economic terms. Being aware of this, the EU is already in the process of introducing not only rules for the use of $5 \mathrm{G}$ networks, but also of providing tools to ensure the prevention and reaction to any security incidents with respect to this new technology. In this vein, as of the end of 2020, Directive (EU) 2018/1972 of the European Parliament and the Council establishing the European Electronic Communications Code (Recast) entered into effect. Another road to introducing $5 \mathrm{G}$ technologies is through the closely related Commission Implementing Regulation (EU) 2020/1070 of 20 July

1 On its gradual implementation in the EU, see European 5G Observatory (n.d.). 
2020 on specifying the characteristics of small-area wireless access points pursuant to Article 57, paragraph 2 of Directive (EU) 2018/1972 of the European Parliament and the Council establishing the European Electronic Communications Code-it defined the characteristics of small-area wireless access points in terms of their maximum volume, restrictions on weight and maximum emission power (being questioned by the opponents of $5 \mathrm{G}$ mostly from among the authors and fans of conspiracy theories and representative of various disinformation camps).

On the other hand, the EU is also pointing to the need to take into account potential foreign influence and to prevent one-sided dependence on foreign providers with respect to electronic communications services, but also other software and hardware providers in general. This issue is already being touched upon by the Regulation (EU) 2019/452 (2019), but with respect to the $5 \mathrm{G}$ network, an important manifesto calling for their protection is foremost in the already mentioned EU Toolbox of risk mitigating measures for cybersecurity of $5 \mathrm{G}$ networks that we shall focus on in the following lines.

\section{The EU digital sovereignty and the 5G-the first steps towards supreme control powers}

The definition of $5 \mathrm{G}$ networks is usually based on the Commission Recommendation of 26 March 2019 on Cybersecurity of 5G networks (Commission Recommendation (EU) 2019/534, II. (2)(a)) and it is used further on in later EU documents. Hence, it is of convenience to offer the definition right here before we move to the details of $5 \mathrm{G}$ security:

' $5 \mathrm{G}$ networks' means a set of all relevant network infrastructure elements for mobile and wireless communications technology used for connectivity and value-added services with advanced performance characteristics such as very high data rates and capacity, low latency communications, ultra-high reliability, or supporting a high number of connected devices. These may include legacy network elements based on previous generations of mobile and wireless communications technology such $4 \mathrm{G}$ or $3 \mathrm{G}$. $5 \mathrm{G}$ networks should be understood to include all relevant parts of the network. (Commission Recommendation (EU) 2019/534)

The report EU Coordinated Risk Assessment of the Cybersecurity of 5G Networks (NIS Cooperation Group, 2019) identified the following differences 
between $5 \mathrm{G}$ and the current situation in existing networks:

A move to software and virtualisation through 'Software Defined Networks (SDN) and Network Functions Virtualisation (NFV)' technologies. This will represent a major shift from traditional network architecture as functions will no longer be built on specialised hardware and software. Instead, functionality and differentiation will take place in the software.

'Network slicing' will make it possible to support to a high degree the separation of different service layers on the same physical network, thus increasing the possibilities to offer differentiated services over the whole network.

Less centralized architecture than in previous generations of mobile network, which allows the network to steer traffic to computing resources and third-party services close to the end-user, thus ensuring low response times. (NIS Cooperation Group, 2019)

Besides the technological aspects, as far as the economic importance of $5 \mathrm{G}$ technology is concerned, according to the Communication from the Commission titled 5G for Europe: An Action Plan, "[w]orldwide 5G revenues should reach the equivalent of $€ 225$ billion in 2025" (Communication COM/2016/0588 final; see also Commission Staff Working Document SWD/2016/0306 final). The Commission therefore launched already back in 2013 a "5G Public-Private-Partnership (5G-PPP) backed by 700 million euro of public funding with the aim of making sure that $5 \mathrm{G}$ technology is available in Europe by 2020" (Communication COM/2016/0588 final).

Still, in order to ensure the security of this new technology and its applications, the EU Toolbox requires that 5G technology will not be dependent on monopolistic market players nor on foreign providers that might both be susceptible to foreign influence interfering with the sovereignty of the EU and its Member States. It is clear that this means adopting a protectionary and precautionary stance with regard to the technology-dependent products and services used in the EU, albeit so far mostly with limitation to the "essential services". However, with the overall use of sensitive 5G technologies in numerous new areas of market and industry, this means that with time, yet larger sectors will need to be protected against interference from actors that are not under the control of the EU sovereigns.

In this regard, so far, the obligations to ensure the sovereignty of the EU are to be imposed only on a limited number of entities as of now-specifically, the electronic communications providers in the EU. Similarly, as with 
the general cybersecurity rules applicable even outside the electronic communications sector (the NIS Directive, the Cybersecurity Act), this means an analogous legislative technique-transferring the duties onto selected entities that need to introduce and observe specific rules to prevent any undue interference by third parties, including their sub-contractors (service and product providers), be it within or outside EU (Kasper \& Krasznay, 2019).

These principles were explicitly voiced in a number of documents issued by the respective EU bodies. We shall focus here primarily on the cybersecurity of the $5 \mathrm{G}$ networks, in which regard the already mentioned Commission Recommendation of 26 March 2019 on Cybersecurity of 5G networks in its Recital 19 differentiates between technical and other factors of cybersecurity:

Addressing cybersecurity risks in $5 \mathrm{G}$ networks should take into account both technical and other factors. Technical factors may include cybersecurity vulnerabilities that may be exploited to gain unauthorised access to information (cyberespionage, be it for economic or political reasons) or for other malicious purposes (cyberattacks aimed at disrupting or destroying systems and data). Important aspects to consider should be the need to protect the networks across their entire lifecycle and the need to cover all relevant equipment, including in the design, development, procurement, deployment, operation and maintenance phases of $5 \mathrm{G}$ networks. (Commission Recommendation (EU) 2019/534)

Recital 20 then explains the other factors of cybersecurity:

Other factors may include regulatory or other requirements imposed on information and communications technologies equipment suppliers. An assessment of the significance of such factors would need to take into account, inter alia, the overall risk of influence by a third country, notably in relation to its model of governance, the absence of cooperation agreements on security, or similar arrangements, such as adequacy decisions, as regards data protection between the Union and the third country concerned, or whether this country is a party to multilateral, international or bilateral agreements on cybersecurity, the fight against cybercrime, or data protection. (Commission Recommendation (EU) 2019/534)

In this vein, the Recommendation also provided that the European Union Agency for Cybersecurity (ENISA) should complete a specific 5G networks threat landscape mapping, and by 1 October 2019 Member States with 
the support of the Commission and together with the ENISA should have completed a joint review of the Union-wide exposure to risks related in particular to $5 \mathrm{G}$ networks.

The Member States submitted the results of their national risk assessments to the Commission and ENISA, based notably on a questionnaire, by July 2019. The respective report was published on 9 October 2019, as "EU coordinated risk assessment of the cybersecurity of 5G networks" (NIS Cooperation Group, 2019). The report identified that two stakeholders are of particular relevance to the cybersecurity of $5 \mathrm{G}$ networks: mobile network operators and telecom equipment manufacturers.

The report identified that mobile network operators (the first group of stakeholders)

providing services in the EU are subject to Union and to Member States' national law, whereby, in particular, they may be subject to general authorisation. Still, the mobile network operators use a range of subcontractors, providing a variety of services (e.g., network management and maintenance, data centres, etc.). (NIS Cooperation Group, 2019)

Such sub-contractors may be located in a different Member State than the mobile network operator's or in a third country.

In addition, the market for telecom equipment (its manufacturers represent the second important group of stakeholders) is

mainly characterised by a handful of global companies capable of supplying large telecommunications operators with the technology required. From a market share perspective, the main suppliers are Huawei, Ericsson and Nokia. Other suppliers include ZTE, Samsung and Cisco10. Some of these suppliers are headquartered in the EU (Ericsson and Nokia) while the others are headquartered outside the EU. Their corporate governance also shows notable differences, for example in terms of level of transparency and type of corporate ownership structure. (NIS Cooperation Group, 2019)

Of course, these new features bring along numerous new security challenges connected to the two groups of stakeholders (mobile network operators with their suppliers, and telecom equipment manufacturers). The report (NIS Cooperation Group, 2019) in this regard identified criteria upon which the risk profiles of individual suppliers can be assessed, notably: 
- The likelihood of the supplier being subject to interference from a nonEU Country, due to

- a strong link between the supplier and a government of a given third country;

- the third country's legislation, especially where there are no legislative or democratic checks and balances in place, or in the absence of security or data protection agreements between the EU and the given third country;

- the characteristics of the supplier's corporate ownership;

- the ability for the third country to exercise any form of pressure, including in relation to the place of manufacturing of the equipment.

- The supplier's ability to assure supply. (NIS Cooperation Group, 2019, p. 22)

In order to mitigate the identified cybersecurity risks, on the basis of national best practices, a toolbox of appropriate, effective and proportionate possible risk management measures at national and EU level were to be prepared in early 2020. According to the Commission Recommendation IV(15), this toolbox was to include:

(a) An inventory of the types of security risks that can affect the cybersecurity of $5 \mathrm{G}$ networks (e.g., supply chain risk, software vulnerability risk, access control risk, risks arising from the legal and policy framework to which suppliers of information and communications technologies equipment may be subject in third countries); and

(b) A set of possible mitigating measures (e.g., third-party certification for hardware, software or services, formal hardware and software tests or conformity checks, processes to ensure access controls exist and are enforced, identifying products, services or suppliers that are considered potentially not secure, etc.). (Commission Recommendation (EU) 2019/534)

On 29 January 2020, the EU Toolbox of Risk Mitigating Measures: Cybersecurity of 5G networks" (NIS Cooperation Group, 2020a) was finally published, on which we shall focus here with regard to its (non)implementation in Slovakia. On the same day, the EU Toolbox was accompanied by the Communication from the Commission to the European Parliament, the Council, the European Economic and Social Committee and the Committee of the Regions "Secure 5G deployment in the EU-Implementing the EU toolbox" (Communication COM/2020/50 final). 
The Toolbox itself invited the EU Member States in particular to:

Strengthen security requirements for mobile network operators (e.g., strict access controls, rules on secure operation and monitoring, limitations on outsourcing of specific functions, etc.);

Assess the risk profile of suppliers; and as a consequence, to apply relevant restrictions for suppliers considered to be high risk;

Ensure that each operator has an appropriate multi-vendor strategy to avoid or limit any major dependency on a single supplier (or suppliers with a similar risk profile), ensure an adequate balance of suppliers at national level and avoid dependency on suppliers considered to be high risk. (NIS Cooperation Group, 2019)

All in all, the EU Toolbox specified (1) strategic measures, (2) technical measures, and (3) supporting actions to be applied by the Member States. From among these, it is mostly strategic measures that may require specific legislation at national level that should be introduced by the EU Member States.

The following eight strategic measures have been identified:

- SM01 Strengthening the role of national authorities;

- SM02 Performing audits on operators and requiring information;

- SM03 Assessing the risk profile of suppliers and applying restrictions for suppliers considered to be high risk-including necessary exclusions to effectively mitigate risks - for key assets;

- SM04 Controlling the use of Managed Service Providers (MSPs) and equipment suppliers' third line support;

- SM05 Ensuring the diversity of suppliers for individual MNOs through appropriate multivendor strategies;

- SM06 Strengthening the resilience at national level;

- SM07 Identifying key assets and fostering a diverse and sustainable 5G ecosystem in the EU;

- SM08 Maintaining and building diversity and EU capacities in future network technologies. (NIS Cooperation Group, 2019)

Clearly, it is mostly SM03, SM04 and SM05 that deal with the potential 
interference of foreign interests into sovereignty of the EU and its Member States. Thereby, risk factor of suppliers should be identified and taken into account, combined with the diversity of suppliers.

The EU Toolbox (NIS Cooperation Group, 2020a) recommends in this regard:

- Establish a framework with clear criteria, taking into account the risk factors;

- Perform rigorous assessments of the risk profile of all relevant suppliers at national level and/or EU level;

- Based on the risk profile assessment, apply restrictions;

- Take steps to ensure that operators have adequate controls and processes in place to manage potential residual risks.

- Establish a legal/regulatory framework which places limit on the types of activity and conditions under which operators are able to outsource particular functions to third parties, while applying restrictions in particular in sensitive parts of the $5 \mathrm{G}$ networks,

- For functions outsourced, impose enhanced security provisions. (NIS Cooperation Group, 2020b)

The Commission thereby called on Member States and relevant Union institutions, agencies and other bodies to swiftly implement the EU Toolbox, namely

- by 30 April 2020, to take concrete and measurable steps to implement the set of key measures recommended in the EU Toolbox conclusions;

- by 30 June 2020, to prepare a report on the state of implementation in each Member States of these key measures. (Communication COM/2020/50 final)

To wrap it up, the EU Toolbox thus aims

to strengthen security requirements for mobile network operators (e.g., strict access controls, rules on secure operation and monitoring, limitations on outsourcing of specific functions, etc.). They should assess the risk profile of suppliers and apply relevant restrictions for suppliers considered to be high risk. (NIS Cooperation Group, 2019)

At the same time, the EU Toolbox requires that each operator has an appropriate multi-vendor strategy to avoid or limit any major dependency on a single supplier (or suppliers with a similar risk profile) (European Commission, 2020). Hence, basically, a solution was chosen to impose obligations on national electronic communication service providers-to protect themselves and provide for ensuring that their suppliers meet the 
necessary security requirements. It is a sort of delegated responsibility that is being transferred onto the service providers, with a backing from national governments that are supposed to draft legislation allowing for identification of potential security risks and their mitigation.

On 24 July 2020, EU Member States, with the support of the Commission and ENISA, published a Report on Member States' Progress in Implementing the EU Toolbox on 5G Cybersecurity, based on the national reports on implementation (NIS Cooperation Group, 2020b). According to the report, good progress has already been achieved for some of the toolbox measures, notably in the following areas:

- The powers of national regulatory authorities to regulate $5 \mathrm{G}$ security.

- Measures aimed at restricting the involvement of suppliers based on their risk profile.

- Network security and resilience requirements for mobile operators are being reviewed. (NIS Cooperation Group, 2020b)

On the other hand, some measures are at a less advanced stage of implementation. According to the report, these were in particular:

- Progress is urgently needed to mitigate the risk of dependency on highrisk suppliers.

- Challenges have been identified in designing and imposing appropriate multi-vendor strategies for individual operators or at national level due to technical or operational difficulties (e.g., lack of interoperability, size of the country, etc.).

- As regards the screening of foreign direct investments (FDI), steps should be taken to introduce national FDI screening mechanism. (NIS Cooperation Group, 2020b; see also Communication 2020/C 99 I/01)

Taking the examples of some Member States, the following approaches were identified as applied in order to implement the EU Toolbox at the national level:

- 'Veto' approaches: Pre-authorisation or notification;

- 'Deny list' approaches: Designating certain suppliers as high risk or untrusted;

- 'Allow list' approaches: Identifying specific suppliers that would be allowed to supply $5 \mathrm{G}$ network equipment or services. (NIS Cooperation Group, 2020b)

As regards the methodology and factors for assessing the risk profile of suppliers, under the report (NIS Cooperation Group, 2020b), specific factors 
applied by the Member States include objective factors such as:

- The origin of suppliers or the risk of interference from third countries (e.g., taking into account the legal and political system of the third country),

- Country-specific information and/or threat intelligence.

For example, in Italy, under the Golden Power law (Law Decree no. 21, 2012), the Government receives notifications concerning the use of equipment or services for deploying $5 \mathrm{G}$ whenever this equipment or service is sourced from extra-EU suppliers. An inter-ministerial Coordination Group advises the Government about the opportunity of vetoing the contract (based on technical analysis) or imposing security measures (NIS Cooperation Group, 2020b).

In the Netherlands, the Decree on safety and integrity of telecommunications of 28 November 2019 provides that untrusted suppliers will be designated on the basis of various criteria, including:

- Service or product comes from a country the legislation of which obliges commercial or private parties to cooperate with the government of that country, or the party providing service of product is a state-owned company,

- Service or product comes from a country with an active offensive intelligence program aimed at the Netherlands and Dutch interests, or the party comes from a country with which the relationship may be strained to a degree that actions that may affect Dutch interests are conceivable. (NIS Cooperation Group, 2020b)

Finally, Finland introduced a rule under which the operators are required to ensure that, in a state of emergency, critical systems and their guidance, maintenance and control can be returned to Finland without delay (NIS Cooperation Group, 2020b).

Still, this only applies to identification of high-risk suppliers. In addition to that, further analysis is yet needed in many Member States to uncover how they identify the appropriate legal basis to impose obligations in terms of diversification of suppliers. So far, in Italy, within the application of the Golden Power law to contracts related to core components, operators have been required to produce a diversification project including both "vertical" diversification (the use of systems from different suppliers in the hardware, virtualization and application layers) and "horizontal" diversification (the use of different software solutions, at application layer) (NIS Cooperation 
Group, 2020b).

However, it may be supposed that many EU Member States have still not even managed to regulate the identification of high-risk suppliers, leaving diversification of suppliers as the final step in their regulatory efforts. From among such countries, we shall provide here an example of the Slovak Republic, which so far has failed to properly implement both the process of identification of high-risk suppliers as well as of diversification of suppliers.

\section{The (non)implementation of EU Toolbox in the Slovak Republic}

In the summer of 2020, the National Security Office of Slovak Republic prepared a bill to amend the currently valid Act on Cybersecurity no. $69 / 2018$. The aim of the proposed bill was to strengthen the legislation in the field of cybersecurity, while focusing on strengthening the powers of the relevant national authorities. The subject matter of the bill is allegedly also the clarification of certain definitions, adjustment of the procedure for cybersecurity certification resulting from the EU Cybersecurity Act, furthermore, the institute of blocking is introduced, and the position of the cybersecurity auditor is to be regulated. The general public as well as public authorities were able to comment on the preliminary information on this legislative process in the period from 10 July 2020 to 23 August 2020.

As part of the preliminary information, two statements were delivered to the preliminary design of the material. The two entities proposed to take into account in the Draft Law the Commission Recommendation (EU) 2019/534 of 26 March 2019 on cybersecurity of $5 \mathrm{G}$ networks, as well as the specific measures resulting from the Toolbox which should be implemented by the Member States, including the Slovak Republic, within the framework of their national capabilities. According to the comments by the two entities, the Draft did not take into account the EU Toolbox at all. The Draft namely proposes only the following modifications-the $§ 27(1)$ of Act no. 69/2018 is to be supplemented by letter e), which gives the National Security Office the power to issue

e) a decision to prohibit or restrict the operator of the essential service from using a specific product, process or service, if this is necessary to ensure cybersecurity or for reasons of the security interest of the Slovak 
Republic.

According to the explanatory memorandum, this suggested provision of $\S 27(1)(e)$, introduces the competence of the National Security Office to prohibit an operator of an essential service to use a specific product, process or service in order to protect the security interests of the Republic.

This brief and very general competence was thereby harshly criticized by several entities during the inter-ministerial comment procedure on the draft bill. A total of 381 comments were submitted to the draft bill, of which 219 were substantial. In particular, the Slovak Cyber Security Association and the American Chamber of Commerce in Slovakia pointed out that the proposed rule introduces a very broad authority for the Office to prohibit or restrict any essential service operator from using a particular product, process or service under a vague condition "if this is necessary to ensure cybersecurity or for reasons of the security interest of the Slovak Republic".

In this context, it is indeed to be considered too broad and general in comparison to the approaches of other countries taken in implementing the EU Toolbox, which are much more readable, pragmatic and especially consistent with the requirements of the EU Toolbox. Let us just remind the reader of the three basic approaches-of a veto, a list of prohibited providers, and a list of allowed providers, with additional rules and criteria for drafting the list and for reviewing the procedure of enlisting. It might suffice to mention that a similar approach is currently being taken by the Ministry of Economy of Slovak Republic when implementing the procedure for application of the EU Regulation on foreign direct investments.

This clearly shows that the draft bill amending Act no. 69/2018 completely omitted the problem of ensuring the security of suppliers (leaving the diversification of suppliers aside completely), which can not be even excused by the activities of the Ministry of Economy when implementing the rules on foreign direct investment, since in this case it was supposed to be the National Security Office who would be the one to prohibit certain products, processes or services, without any details on how to draw a list of "highrisk suppliers" or "high-risk products, processes or services"- based on what parameters, how to ensure the process is transparent and objective, and how to appeal this decision (on enlisting).

Other countries, in contrast, answer all these questions in their national legislation, provide for that the list is continuously being updated, space is created for a "defence" to be invoked by the affected suppliers entered in this 
list, allowing them to demonstrate that the hybrid threats and political risks on their side are not present or no longer present. This approach is thus characterized by the introduction of precise evaluation rules, procedural rules and transitional periods to align existing contractual relationships with suppliers, who will be included in the list.

It is precisely this approach that is to be considered appropriate and correct, meeting the requirements of the EU Toolbox with fair and transparent rules, while still leaving the risk assessment to the state as the supreme guarantor of security, not to essential service operators.

Taking the recommendations and foreign models of regulation into account, one of the commenting entities, the already mentioned Slovak Cyber Security Association proposed a new wording of the relevant provisions of the Slovak Cybersecurity Act ${ }^{2}$ as follows:

$\S 27 \mathrm{a}$

The Office's powers in assessing hybrid threats and political risks of third parties and other persons

(1) The Office shall prohibit or restrict by a decision pursuant to a special regulation (Act no. 71/1967 Coll. On Administrative Procedure (Administrative Procedure) as amended) the operator of essential service, or a third party according to $§ 19(2)$ or another person to use the services, products or processes of a third party or other person with a high or medium risk identified under the conditions pursuant to $§ 27 \mathrm{a}$, if this is necessary to ensure cybersecurity or for reasons of security interest of the Slovak Republic.

(2) The Office shall draw up and publish in the single cybersecurity information system a list of high-risk third parties or other persons. The Office shall assess the risk of third parties or other persons in the context of a risk analysis taking into account the following criteria: (a) hybrid threats (Joint Communication to the European Parliament and the Council A common framework for combating hybrid threats European Union response: https://eur-lex.europa.eu/legal-content/en/ ALL/?uri=CELEX:52016JC0018 (04.10.2020) and political risks, in particular the potential or actual impact of a country outside the European Union ("Third country") onto the third party or other person, (b) the

$2 \quad$ The draft bill to amend Act no. 69/2018, with all the comments, is available at https://www. slov-lex.sk/legislativne-procesy/SK/LP/2020/400. 
legislation of the third country in the field of protection of fundamental human rights and freedoms, protection of personal data and protection of information; c) the ownership and management structure of the third party or other person; d) the types of vulnerabilities and cybersecurity incidents detected within the scope of the third party or other person, together with the manner and time period of their elimination; e) the extent to which the third party or other person controls the production and delivery process of hardware or software and the risks to the production and delivery process of hardware or software. The Office shall regularly update the risk list of third parties and other persons at least every 12 months from the last risk analysis or whenever there is a significant change affecting the identified risks or the third parties.

(3) The output of the risk analysis pursuant to (2) is: a) high risk, if the third party or other person poses high risks to cybersecurity or security interests of the Slovak Republic, while the identified risks cannot be reduced by taking appropriate measures, b) medium risk, if the third party or other person represents high risks for cybersecurity or security interests of the Slovak Republic, while the identified risks can be reduced by taking appropriate measures to the level of low or none, c) low risk, if a third party or other person represents low risks for cybersecurity or security interests of the Slovak Republic and identified risks it can be eliminated by taking appropriate measures, or d) no risk, provided the third party or other person presents no or only negligible risks to cybersecurity or the security interests of the Slovak Republic.

(4) If the output of the risk analysis referred to in (2) is high or medium risk, the Office shall include the third party or other person on the list pursuant to (1) together with a quantification of the risk that gave rise to the enlisting of the third party or other person. The third party or other person on the list pursuant to (1) shall be entitled to submit objections to the Office, together with evidence demonstrating the absence or reduction of a high or medium risk. The Office shall decide on the objections of the third party or other person within [...] days from the date of their submission, in justified cases the Office is entitled to extend this period, which is to be notified to the third party or other person before the expiration of the original period.

(5) Where the output of the risk analysis referred to in (2) is: (a) high risk, the operator of the essential service, the third party or other person may not start using the services, products or processes of that third 
party or other person and, in the case of existing relationships, must cease using the services, products or processes of that third party or other person within [...] months from the date of listing of the third party or other person pursuant to (1), b) medium risk, the operator of the essential service, the third party or other person may not start using the services, products or processes of that third party or other person and may use the services, products or processes of that third party in existing relationships with the third party or another person to the extent valid on the date of listing of the third party or other person pursuant to (1).

(6) In the event that the operator of the essential service does not comply with (5), the Office is entitled to proceed according to (1).

Wording of the new §34a of the Act was suggested as follows:

$\S 34 \mathrm{a}$

Transitional provisions effective from [date]

The Office shall perform the first risk analysis pursuant to $§ 27 \mathrm{a}(2)$ and shall prepare and publish the first list according to $§ 27 \mathrm{a}$ (1) within three months from the date this Act becomes effective.

Hence, material, procedural as well as transitional rules were suggested anew in order to provide a complex regulation of the matter at hand.

However, based on the EU Toolbox implementation report mentioned above, it is clear that there are also other possible solutions-mainly that of using veto or creating a "positive" list of allowed suppliers. The commenting institution in its proposed new wording also failed to take into account the need to diversify suppliers, which also needs to be regulated-e.g., following the Italian example of both vertical and horizontal diversification. The legislative process hence still needs to be closely scrutinized and commented in order to reach the required level of security-one of the main goals to be achieved within the concept of "EU digital sovereignty".

\section{Conclusions}

Slovak Republic in its ongoing process of amending Act no. 69/2018 on Cybersecurity failed to take note of the EU Toolbox and to implement its requirements so as to ensure the goal of digital sovereignty of both the EU as 
well as that of Slovakia. In this brief article, we have provided an overview of various regulatory models used in other EU Member States that Slovakia and other EU Member States can follow in implementing the Toolbox-both with regard to ensuring the security of suppliers, as well as with respect to diversification of suppliers. With the former, we would rather plead for a positive list of "allowed" suppliers, based on objective criteria, which may be formed, e.g., according to the Dutch example. This prevents the negative labelling of some of the suppliers by the official authorities of the EU Member States and instead of their opposing to inclusion in a "banned" list, they can rather show evidence as to their fulfilment of all the criteria required in order to be included in the "White list". Of course, the criteria should not be manifestly discriminatory, rather they should be explicitly emphasizing the security aspects of the criteria selected. Secondly, with regard to diversification, the legal regulation should certainly also take into account material, procedural as well as transitional aspects of the matter-respecting the existing contracts and/or providing for their gradual limitation in scope and duration so as to reach the goal of diversification in the very end.

\section{Acknowledgements}

The article was prepared within the implementation of the project no. 20-27227S 'The Advent, Pitfalls and Limits of Digital Sovereignty of the European Union' funded by the Czech Science Foundation (GAČR).

Tomáš Gábriš is a researcher at the Faculty of Law, Palacký University Olomouc (Czech Republic) and at the Institute of State and Law of the Slovak Academy of Sciences (Slovak Republic). His main expertise is theory of law and law of modern technologies. He regularly acts as a national rapporteur in the preparation of analyses in the field of law of modern technologies for the needs of the European Commission. As part of his legislative expertise, he was a member of the Recodification Commission for Civil Procedural Law, which successfully prepared three new civil procedural codes (Act no. 160-162/2015 Coll.), and until 2020 he was a member of the recodification commission for the preparation of the new Civil Code. Currently, he is a member of the Legislative Council of the Government of the Slovak Republic. He is the author of ten scientific monographs, co-author of ten textbooks, and in total the author of more than 300 publications. 
Ondrej Hamulák is a senior lecturer at the Faculty of Law, Palacký University Olomouc (Czech Republic), an adjunct professor in EU Strategic Legal Affairs, TalTech Law School (Estonia) and researcher at the Faculty of Law, Comenius University in Bratislava (Slovakia). He specialises on the relations and interactions between EU law and national law, the theoretical impacts of the membership in the EU on state sovereignty, the legitimacy and rule of law within the EU and systems of human rights protection on the supranational level. As a member of Jean Monnet Network "European Union and the Challenges of Modern Society" (611293-EPP-1-2019-1-CZ-EPPJMO-NETWORK), he analyses the raise of EU regulatory power within digital space and tacit creation of EU digital sovereignty.

\section{References}

Andraško, J.; Mesarčík, M. and Hamulák, O. (2021), 'The regulatory intersections between artificial intelligence, data protection and cyber security: challenges and opportunities for the EU legal framework,' $A I$ \& Soc., vol. 36, no. 2, pp. 623-636. https://doi.org/10.1007/s00146-020-01125-5

Camilleri, J. (1992), The End of Sovereignty? The Politics of a Shrinking and Fragmenting World, Aldershot: Edward Elgar Publishing Ltd.

Communication from the Commission to the European Parliament, the Council, the European Economic and Social Committee and the Committee of the Regions 5G for Europe: An Action Plan, COM/2016/0588 final, 14.9.2016.

Communication from the Commission to the European Parliament, the Council, the European Economic and Social Committee and the Committee of the Regions Secure 5G deployment in the EU - Implementing the EU toolbox, COM/2020/50 final, 29.1.2020.

Communication from the Commission. Guidance to the Member States concerning foreign direct investment and free movement of capital from third countries, and the protection of Europe's strategic assets, ahead of the application of Regulation (EU) 2019/452 (FDI Screening Regulation), 2020/C 99 I/01, OJ C 99I, 26.3.2020.

Commission Recommendation (EU) 2019/534 of 26 March 2019 Cybersecurity of 5G networks, OJ L 88, C/2019/2335, 29.3.2019, pp. 42-47.

Commission Staff Working Document 5G Global Developments Accompanying the document Communication from the Commission to the European Parliament, the Council, the European Economic and Social Committee and the Committee of the Regions 5G for Europe: An Action Plan, SWD/2016/0306 final, 14.9.2016. 
Directive 2016/1148 of the European Parliament and of the Council of 6 July 2016 concerning measures for a high common level of security of network and information systems across the Union, OJ L 194, 19.7.2016, pp. 1-30.

European 5G Observatory (n.d.), [Home page]. Retrieved from http://5gobservatory. eu/ [accessed 11 Nov 2020]

European Commission (2020), Secure 5G Networks: Questions and Answers on the EU Toolbox, 29.1.2020. Retrieved from https://ec.europa.eu/commission/ presscorner/detail/en/qanda_20_127 [accessed 11 Nov 2020]

Hamul'ák, O. (2015), Lessons from the "constitutional mythology" or how to reconcile the concept of state sovereignty with European integration,' DANUBE: Law, Economics and Social Issues Review, vol. 6, no. 2, pp. 75-90. https://doi.org/10.1515/danb-2015-0005

Hamul'ák, O.; Kiss, L. N.; Gábriš, T. \& Kocharyan, H. (2021), 'This content is not available in your country. A general summary on geo-blocking in and outside the European Union,' International and Comparative Law Review, vol. 21, no. 1, pp. 153-183. https://doi.org/10.2478/iclr-2021-0006

Kabat-Rudnicka, D. (2020), 'Autonomy or sovereignty: the case of the European Union,' International and Comparative Law Review, vol. 20, no. 2, pp. 73-92. https://doi.org/10.2478/iclr-2020-0018

Kasper, A. \& Krasznay, C. (2019), 'Towards pollution-control in cyberspa 7 ce: problem structure and institutional design in international cybersecurity,' International and Comparative Law Review, vol. 19, no. 2, pp. 76-96. https://doi.org/10.2478/iclr-2019-0015

Lindahl, H. (2006), 'Sovereignty and symbolization,' in N. Walker (ed.) Relocating Sovereignty, Abingdon \& New York: Ashgate Publishing, pp. 53-78.

Maiolo, F. (2007), Medieval Sovereignty: Marsilius of Padua and Bartolus of Saxoferrato, Delft: Eburon Academic.

National Security Office (2020), Draft bill to amend Act no. 69/2018, with comments, Office of the Government of the Slovak Republic, Department of Legislation of Other Central State Administration Bodies. Retrieved from https:/www.slovlex.sk/legislativne-procesy/SK/LP/2020/400 [accessed 11 November 2020].

NIS Cooperation Group (2019), EU Coordinated Risk Assessment of the Cybersecurity of 5 G Networks, Report, European Commission, 9.10.2019.

NIS Cooperation Group (2020a), Cybersecurity of 5G Networks. EU Toolbox of Risk Mitigating Measures, CG Publications, European Commission, 01/2020.

NIS Cooperation Group (2020b), Report on Member States' Progress in Implementing the EU Toolbox on 5G Cybersecurity, European Commission, July 2020.

Regulation 2019/452 of the European Parliament and of the Council of 19 March 2019 establishing a framework for the screening of foreign direct investments into the Union, OJ L 79 I, 21.3.2019, pp. 1-14. 
Regulation 2019/881 of the European Parliament and of the Council of 17 April 2019 on ENISA (the European Union Agency for Cybersecurity) and on information and communications technology cybersecurity certification and repealing Regulation (EU) No 526/2013 (Cybersecurity Act) (Text with EEA Relevance), OJ L 151, 7.6.2019, pp. 15-69.

Roguski, P. (2019), 'Layered sovereignty: adjusting traditional notions of sovereignty to a digital environment,' in 11th International Conference on Cyber Conflict: Silent Battle, Tallinn: NATO CCD COE Publications.

https://doi.org/10.23919/CYCON.2019.8756900

Tropina, T. \& Callanan, C. (2015), Self- and Co-regulation in Cybercrime, Cybersecurity and National Security, Cham: Springer.

https://doi.org/10.1007/978-3-319-16447-2 